\title{
Splendid Hybrids: The Effects of a Tiger Beetle Hybrid Zone on Apparent Species Diversity
}

\author{
Mathew L. Brust, ${ }^{1}$ W. Wyatt Hoback, ${ }^{2}$ and Stephen M. Spomer ${ }^{3}$ \\ ${ }^{1}$ Department of Biology, Chadron State College, Chadron, NE 69337, USA \\ ${ }^{2}$ Department of Biology, University of Nebraska at Kearney, 905 W 25th Street, Kearney, NE 68849, USA \\ ${ }^{3}$ Department of Entomology, University of Nebraska Lincoln, 103 Entomology Hall, Lincoln, NE 68583-0816, USA
}

Correspondence should be addressed to W. Wyatt Hoback, hobackww@unk.edu

Received 2 October 2011; Revised 11 January 2012; Accepted 11 January 2012

Academic Editor: Brian Forschler

Copyright (C) 2012 Mathew L. Brust et al. This is an open access article distributed under the Creative Commons Attribution License, which permits unrestricted use, distribution, and reproduction in any medium, provided the original work is properly cited.

Nonexpert citizen groups are being used to monitor species to track ecosystem changes; however, challenges remain for proper identification, especially among diverse groups such as beetles. Tiger beetles, Cicindela spp., have been used for biological diversity monitoring because of their diversity and the ease of recognition. The finding of an apparent hybrid zone among Cicindela denverensis Casey, Cicindela limbalis Klug, and Cicindela splendida Hentz in central Nebraska prompted a detailed study of the biogeography of this species group within Nebraska, a test of characteristics that could be used by citizen scientists, and limited breeding experiments. This study suggests that while C. denverensis appears to hybridize with both C. limbalis and C. splendida within the hybrid zone, all three species maintain their integrity across most of their ranges, largely occupy unique geographic regions, and at least $C$. denverensis and $C$. splendida cooccur in many areas with no evidence of hybridization. Evidence of hybridization between $C$. limbalis and C. splendida was found at only two sites. Furthermore, breeding experiments with virgin C. splendida and $C$. denverensis showed that they are capable of producing hybrid larvae in the laboratory. The presence of morphological intergrades serves as a cautionary note when using biological indicator species.

\section{Introduction}

Hybridization of distinct lineages has been recognized as an important area of evolutionary research since the time of Charles Darwin. Although much of the past research has been on plant hybridization, attention to animal species has been increasing and has become the subject of focused research by evolutionary biologists [1-4]. Unfortunately for the field of conservation biology, hybridization can be extremely problematic. Moreover, the challenge of hybridization to the conservation of unique species has increased as anthropomorphic changes to environment and globalization and introduction of exotic species have combined to increase interactions among species [5].

As global changes take place and loss of biodiversity is a growing concern, many research organizations have sought to increase biological monitoring by citizen groups. A growing number of examples exist for monitoring of aquatic ecosystems for pollution [6]. More recently, citizen scientist groups have successfully detected both invasive species [7] and rare native species such as the nine-spotted lady beetle, Coccinella novemnotata [8]. Citizen science programs have also been used to collect data over broad scales such as the case for determining monarch butterfly, Danaus plexippus, migration routes [9].

Despite these and many other benefits in the use of citizen scientists for ecosystem monitoring, many challenges remain, including training citizen scientists, coordinating monitoring programs, and ensuring the accuracy of identification (e.g., [6, 7]). Relatively, few citizen monitoring programs exist for terrestrial invertebrate diversity, likely as a result of the enormous diversity of terrestrial insects. Among groups that have been monitored, dragonflies, butterflies, and ladybird beetles have received the most attention. Another candidate group is the tiger beetles, Coleoptera: Carabidae: Cicindelinae.

The tiger beetles of North America have been studied thoroughly and are well known even to the subspecies level, 
TABLE 1: Identification characters used to differentiate between species in the Cicindela splendida group.

\begin{tabular}{lccc}
\hline Character & C. denverensis & C. limbalis & C. splendida \\
\hline Dorsal head & Green to blue-green & Purple, red, or dull red & Green to blue \\
Margins of head & Green to blue-green & Green to blue & Green to blue \\
Dorsal pronotum & Green to blue-green & Purple, red, or dull red & Green to blue \\
Margins of pronotum & Green to blue-green & Green to blue & Green to blue \\
Elytra & Green to blue-green & Purple, red, or dull red & Red, purple, or (rarely) green \\
Margins of elytra & Green to blue-green & Green to blue & Green to blue \\
Proepisternum & Green to blue & Red to orange & Green to blue \\
\hline
\end{tabular}

TABLE 2: Locality information for specimens of C. denverensis examined.

\begin{tabular}{|c|c|c|c|c|}
\hline Species & County & $\begin{array}{c}\text { County } \\
\text { total }\end{array}$ & Location & $\begin{array}{l}\text { Location } \\
\text { total }\end{array}$ \\
\hline \multirow{21}{*}{ C. denverensis } & Banner & 2 & $\begin{array}{c}\text { Bull } \\
\text { Canyon }\end{array}$ & 2 \\
\hline & Buffalo & 54 & Amherst & 8 \\
\hline & & & $\begin{array}{c}\text { Cherry } \\
\text { Creek }\end{array}$ & 3 \\
\hline & & & Kearney & 43 \\
\hline & Custer & 13 & Ansley & 13 \\
\hline & Dawes & 4 & Chadron & 2 \\
\hline & & & Crawford & 2 \\
\hline & Dawson & 103 & Gothenburg & 41 \\
\hline & & & Sumner & 62 \\
\hline & Garfield & 9 & Burwell & 9 \\
\hline & Kimball & 1 & Pine Bluffs & 1 \\
\hline & Red Willow & 1 & McCook & 1 \\
\hline & Scotts Bluff & 14 & Scottsbluff & 14 \\
\hline & Sherman & 90 & E Loup City & 3 \\
\hline & & & Hazard & 77 \\
\hline & & & $\begin{array}{l}\text { W Loup } \\
\text { City }\end{array}$ & 10 \\
\hline & Sioux & 58 & Crawford & 6 \\
\hline & & & Harrison & 52 \\
\hline & Valley & 11 & Arcadia & 3 \\
\hline & & & Elyria & 4 \\
\hline & & & Ord & 4 \\
\hline \multicolumn{3}{|c|}{ Total counties $=12$} & $\begin{array}{c}\text { Total sites }= \\
20\end{array}$ & Total $=360$ \\
\hline
\end{tabular}

although variation is considerable and the validity of many is still debated [11]. Because many tiger beetles are diurnally active predators, regionally diverse, and identified by color markings, they can potentially be useful for citizen groups as a biological indicator group [12]. Indeed, worldwide, tiger beetles have been used to predict species richness patterns in other taxa and have shown strong correlation with butterfly species richness [13-15]. In the United States, tiger beetle diversity varies by region, with the highest diversity found in the southwest and generally lower diversity found in the north [11]. The state of Nebraska has recorded 32 species of tiger beetles $[16,17]$. Among the 93 Nebraska counties, as few as 0 and as many as 22 tiger beetle species have been
TABLE 3: Locality information for specimens of C. limbalis examined.

\begin{tabular}{|c|c|c|c|c|}
\hline Species & County & $\begin{array}{c}\text { County } \\
\text { total }\end{array}$ & Location & $\begin{array}{c}\text { Location } \\
\text { total }\end{array}$ \\
\hline \multirow{22}{*}{ C. limbalis } & \multirow[t]{2}{*}{ Buffalo } & \multirow[t]{2}{*}{4} & Cherry Creek & 2 \\
\hline & & & Kearney & 2 \\
\hline & Burt & 1 & Decatur & 1 \\
\hline & Butler & 10 & Bellwood & 10 \\
\hline & Cass & 1 & Murdock & 1 \\
\hline & Douglas & 8 & Omaha & 8 \\
\hline & \multirow[t]{2}{*}{ Greeley } & \multirow[t]{2}{*}{4} & Scotia & 2 \\
\hline & & & Wolbach & 2 \\
\hline & Howard & 28 & St. Paul & 28 \\
\hline & Lancaster & 4 & Lincoln & 4 \\
\hline & Merrick & 4 & Palmer & 4 \\
\hline & \multirow[t]{2}{*}{ Nance } & \multirow[t]{2}{*}{5} & Fullerton & 3 \\
\hline & & & Palmer & 2 \\
\hline & Polk & 1 & Osceola & 1 \\
\hline & \multirow[t]{2}{*}{ Sarpy } & \multirow[t]{2}{*}{4} & Ashland & 1 \\
\hline & & & Gretna & 3 \\
\hline & Saunders & 3 & Otoe Creek & 3 \\
\hline & \multirow[t]{2}{*}{ Sherman } & \multirow[t]{2}{*}{26} & E Loup City & 18 \\
\hline & & & Hazard & 8 \\
\hline & \multirow[t]{2}{*}{ Valley } & \multirow[t]{2}{*}{2} & Arcadia & 1 \\
\hline & & & Davis Creek & 1 \\
\hline & Washington & 3 & $\begin{array}{c}\text { County Line } \\
\text { Road }\end{array}$ & 3 \\
\hline & tal counties $=15$ & & Total sites $=22$ & Total $=108$ \\
\hline
\end{tabular}

recorded with the highest numbers recorded in areas with the most intensive sampling [16]. No pattern in number of species has been detected by latitude, ecoregion, or county size [16].

Among the tiger beetles occurring in Nebraska, one group, the Cicindela splendida group, remains controversial. The group consists of three named species, Cicindela denverensis Casey, Cicindela limbalis Klug, and Cicindela splendida Hentz, which are morphologically very similar and may only be readily separated by color. Schincariol and Freitag [18] determined that each of these three forms represented valid species and that they could be distinguished on the basis of elytral pattern, percent maculation, elytral color, and nonsensory setae number. These authors noted that the genitalia were very similar in all three of these forms. Interspecific copulation between species in this group has 
TABLE 4: Locality information for specimens of C. splendida examined.

\begin{tabular}{|c|c|c|c|c|}
\hline Species & County & $\begin{array}{c}\text { County } \\
\text { total }\end{array}$ & Location & $\begin{array}{l}\text { Location } \\
\text { total }\end{array}$ \\
\hline & Buffalo & 70 & Amherst & 3 \\
\hline & & & Cherry Creek & 7 \\
\hline & & & Kearney & 57 \\
\hline & & & Pleasanton & 3 \\
\hline & Butler & 11 & Bellwood & 11 \\
\hline & Cass & 4 & Murdock & 2 \\
\hline & & & $\begin{array}{l}\text { Nebraska } \\
\text { City }\end{array}$ & 2 \\
\hline & Custer & 6 & Ansley & 5 \\
\hline & & & Merna & 1 \\
\hline & Dawson & 37 & Gothenburg & 26 \\
\hline & & & Sumner & 11 \\
\hline & Douglas & 7 & Omaha & 7 \\
\hline & Franklin & 28 & Bloomington & 27 \\
\hline & & & Naponee & 1 \\
\hline & Gage & 1 & Virginia & 1 \\
\hline & Garfield & 2 & Burwell & 2 \\
\hline & Gosper & 4 & Elwood & 4 \\
\hline & Greeley & 6 & Scotia & 4 \\
\hline & & & Wolbach & 2 \\
\hline & Harlan & 9 & $\begin{array}{c}\text { Harlan } \\
\text { Reservoir }\end{array}$ & 1 \\
\hline \multirow[t]{21}{*}{ C. splendida } & & & Oxford & 5 \\
\hline & & & Ragan & 3 \\
\hline & Howard & 14 & Ashton & 4 \\
\hline & & & St. Paul & 10 \\
\hline & Lancaster & 22 & Lincoln & 19 \\
\hline & & & Spring Creek & 3 \\
\hline & Merrick & 3 & Palmer & 3 \\
\hline & Nance & 1 & Fullerton & 1 \\
\hline & Phelps & 14 & S Holdrege & 14 \\
\hline & Red Willow & 4 & McCook & 4 \\
\hline & Saline & 1 & Crete & 1 \\
\hline & Sarpy & 2 & Gretna & 2 \\
\hline & Saunders & 1 & Otoe Creek & 1 \\
\hline & Scotts Bluff & 2 & Scottsbluff & 2 \\
\hline & Sherman & 133 & E Loup City & 48 \\
\hline & & & Hazard & 70 \\
\hline & & & W Loup City & 15 \\
\hline & Sioux & 8 & Harrison & 8 \\
\hline & Valley & 7 & Arcadia & 3 \\
\hline & & & Davis Creek & 1 \\
\hline & & & Ord & 3 \\
\hline & 1 & & $\begin{array}{c}\text { Total sites }= \\
41\end{array}$ & Total $=397$ \\
\hline
\end{tabular}

been reported in the literature [19], and, in Nebraska is frequently observed. However, these observations do not verify that these matings result in offspring or if offspring are viable. Moreover, Schincariol and Frietag [18] suggested that
TABLE 5: Colors used in character analyses (from [10]).

\begin{tabular}{lc}
\hline Code & Color definition \\
\hline 1 & Very deep purplish red (257) \\
2 & Deep red (13) \\
3 & Grayish reddish orange (39) \\
4 & Dark greenish yellow (103) \\
5 & Deep yellowish green (132) \\
6 & Deep bluish green $(161)$ \\
7 & Deep blue, royal blue (179) \\
8 & Deep violet $(208)$ \\
\hline
\end{tabular}

spermatophore ejection by the female allows these species to maintain their integrity.

During extensive sampling by the senior author, a number of apparent hybrids between Cicindela denverensis and C. limbalis were collected in central Nebraska from a zone extending north to south and about $30 \mathrm{~km}$ wide [17]. Apparent hybrids between two other species, $C$. denverensis and $C$. splendida, occur regularly across a zone in central Nebraska extending north to south and approximately $80 \mathrm{~km}$ wide.

In this study we conducted a morphological study of members of the Cicindela splendida group throughout Nebraska and did selective interspecific breeding experiments. In order to determine the occurrence of hybrids within this group, we tested the following hypotheses: (1) hybrids are most frequent in specific geographic areas, (2) the geographic areas in which hybrids are most frequent are related to the range and relative abundance of the species present, and (3) hybrid offspring would be produced in the laboratory using virgin males and females with interspecific pairings.

\section{Materials and Methods}

2.1. Character Analyses and Geographic Location. A total of 865 Nebraska specimens from this group were examined from the personal collections of Mathew Brust, Steve Spomer, and Paul Nabity (Tables 2, 3, 4). Individuals were identified to species based on the characters presented in Tables 1 and 6. Based on these characters, any specimen with a distinct blue to dark green margin on the head and pronotum was classified as $C$. limbalis, while any lacking this character but having the color of the head and pronotum differing from the color of the elytra or having distinct dark green to blue margins on the elytra was considered C. splendida. These designations were made to allow analyses with the null assumption of no hybridization.

Character analysis generally followed those of Schincariol and Frietag [18] and Schincariol [20]. One additional grade for color based on Kelly and Judd [10] was added to account for an unusual morph that was found at several locations. Thus, elytral color (1-8) and pronotal color (1-8) were scored for each specimen (Table 5) and analyzed in order to determine hybridization.

Maculation characters were also analyzed to test whether maculation could be used to differentiate these species, as suggested by Schincariol and Frietag [18]. The following 
TABLE 6: Variations in color found in apparent hybrids between species in the Cicindela splendida group.

\begin{tabular}{|c|c|c|c|}
\hline Character & C. denverensis $\times$ limbalis & C. denverensis $\times$ splendida & C. limbalis $\times$ splendida \\
\hline Dorsal head & $\begin{array}{c}\text { Orange-green, yellow-green, or } \\
\text { green }\end{array}$ & Green to blue & Orange-green to red \\
\hline Margins of head & Green-blue to blue & Green to blue & $\begin{array}{l}\text { Orange-green to red, limited } \\
\text { greenish }\end{array}$ \\
\hline Dorsal pronotum & $\begin{array}{c}\text { Orange-green, yellow-green, or } \\
\text { green }\end{array}$ & Green to blue & Orange-green to red \\
\hline Margins of pronotum & Green-blue to blue & Green to blue & $\begin{array}{l}\text { Orange-green to red, limited } \\
\text { greenish }\end{array}$ \\
\hline Elytra & $\begin{array}{c}\text { Orange-green, yellow-green, or } \\
\text { green }\end{array}$ & $\begin{array}{l}\text { Bronze, orange-green, } \\
\text { yellow-green or green }\end{array}$ & Purple, red, or dull red \\
\hline Margins of elytra & Green-blue to blue & Green to blue & $\begin{array}{l}\text { Orange-green to red, limited } \\
\text { greenish }\end{array}$ \\
\hline Proepisternum & At least partially red or orange & Green to blue & At least partially red or orange \\
\hline
\end{tabular}

characters of maculation were graded: development of the humeral lunule (A-E), development of the middle band (A-E), development of the apical lunule (A-E), and overall development of maculation (A-E).

All characters were then analyzed across latitude and longitude using the PROC GLM procedure [21] with each one degree increment represented as a categorical variable (latitude $=1-3$, longitude $=1-9$ ). The results were checked for latitude by longitude interactions as well. When significant differences $(P<0.05)$ were found for a character by latitude or longitude, a post-hoc Tukey test was performed.

2.2. Hybridization in the Laboratory. Adults of $C$. denverensis and C. splendida emerge briefly in Fall after pupation, but do not mate until spring $[11,22]$. Specimens for hybridization experiments were collected in October from the vicinity of Kearney, Nebraska. Three conspecific pairs consisting of a male $C$. denverensis and a female C. splendida were placed in individuals plastic aquaria (3.8 liter) with loess soil (approximately $70 \mathrm{~cm}$ deep) from collection sites. The aquaria were maintained at room temperature for about one week and were then placed into a refrigerator (approximately $6^{\circ} \mathrm{C}$ ) for 8 weeks because a cool period is needed to trigger diapause and that this diapause is required for sexual maturity [22]. Aquaria were then placed at room temperature and adults were allowed to mate and oviposit. Resulting eggs and larvae were counted once the female in each aquarium had died. Adults and resulting larvae were fed apterous Drosophila melanogaster Meigen.

\section{Results}

3.1. Character Analyses and Geographic Location. Examination of more than 860 specimens belonging to the C. splendida group revealed considerable variation in elytral and pronotal color among the group (Figure 1, Table 6). For $C$. denverensis, no significant differences in elytral color were detected, while the elytral coloration for both C. splendida and C. limbalis differed significantly by longitude (Figures 4 , 6 , and 8 ). Elytral color converged for all three species between approximately $98^{\circ}$ and $100^{\circ}$ west longitude (Figures 10,11 , and 13).

Pronotal colors also varied by region with significant differences found for C.denverensis, C. limbalis, and C. splendida (Figures 5, 7, and 9). Among species, no latitude by longitude interactions were found. In the region between $98^{\circ}$ and $100^{\circ}$ west longitude, the pronotal color of C. limbalis became significantly more like that of $C$. denverensis (Figure 7).

Character analyses based on Schincariol and Freitag [18] revealed no consistent differences in elytral maculation that would allow the three species to be consistently distinguished. Significant differences in markings occurred for all species across their distribution for at least some of the elytral markings. For $C$. denverensis, differences in total maculation, humeral lunule, middle band, and apical lunule varied by longitude (Figure 1). For both C. limbalis and C. splendida significant differences were detected for the middle band and apical lunules but not for total maculation (Figures 2 and 3).

3.2. Hybridization in the Laboratory. The three females used in the hybridization experiments produced 66,23 , and 4 eggs respectively. Of these eggs, 39,12 , and 0 hatched, respectively. Attempts were made to rear the larvae to adulthood but all died before maturity as a result of mold infection.

\section{Discussion}

Pearson and Cassola [12] suggest that tiger beetles represent a well-characterized fauna that is suitable for use by nonexperts as a biological indicator group. In Nebraska, the three species examined in this study display an apparent hybrid zone based on color and markings across the central region of the state. Field observations of interspecific pairings along with the small-scale laboratory breeding experiments reveal that hybridization is possible, although these results should be cautiously interpreted. To determine the extent of hybridization, molecular studies over a large region should be conducted as was accomplished for Cicindela dorsalis Say [23] and C. splendida and C. limbalis [24] Further studies of interbreeding and rearing conditions should also be 


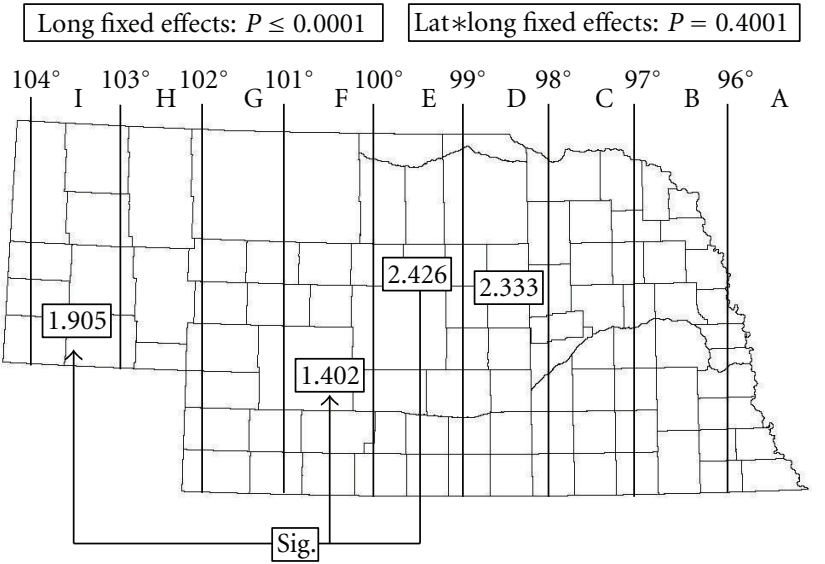

(a)

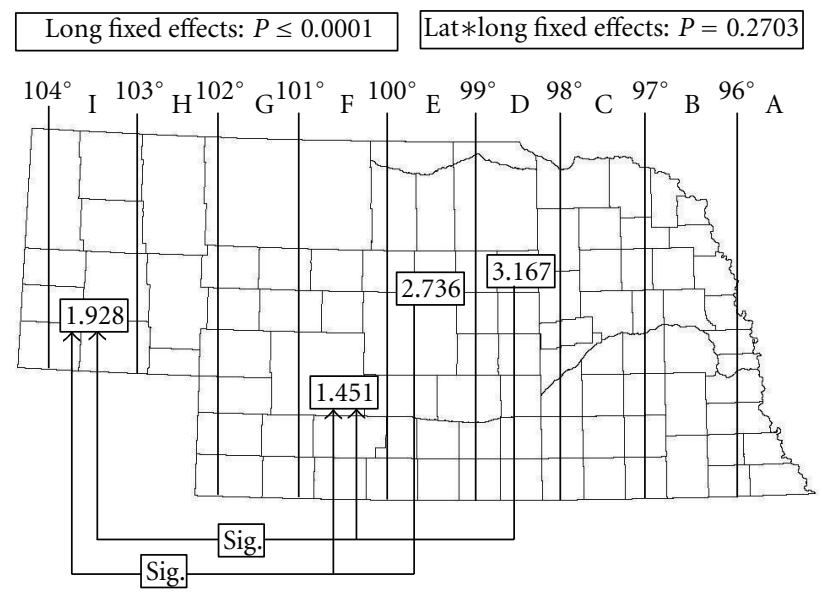

(c)
Long fixed effects: $P \leq 0.0057$ Lat $*$ long fixed effects: $P=0.0108$

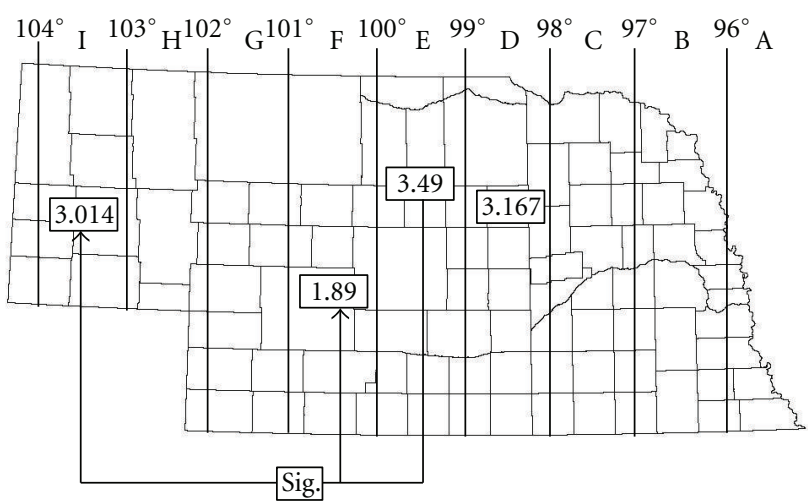

(b)

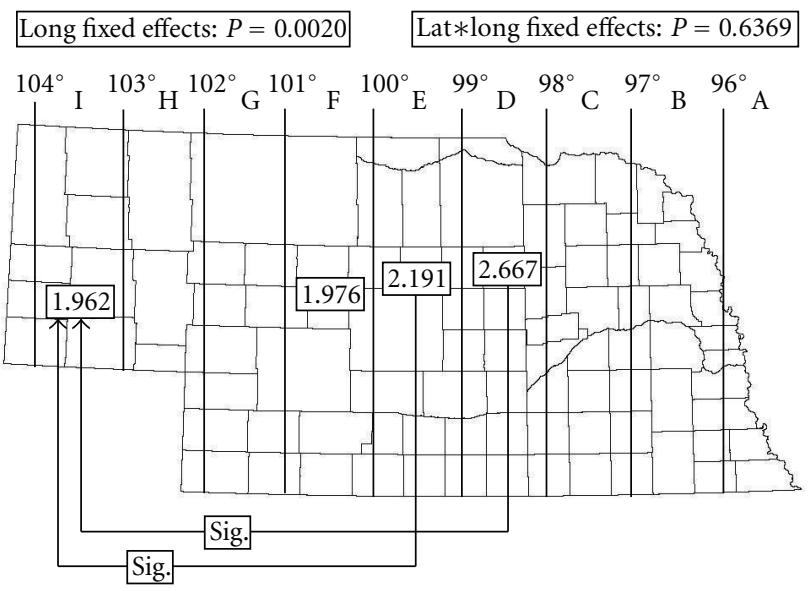

(d)

Figure 1: Elytral maculation character states for C. denverensis (adapted from [18]). (a) Total maculation, (b) humeral lunule, (c) middle band, and (d) apical lunule. Significant differences between longitudes shown by arrows and mean value presented in each longitudinal grouping. Fixed effects and effects of latitude by longitude interactions presented at top of each map.

\section{Long fixed effects: $P=0.0021$ Lat $*$ long fixed effects: $P=0.8704$}

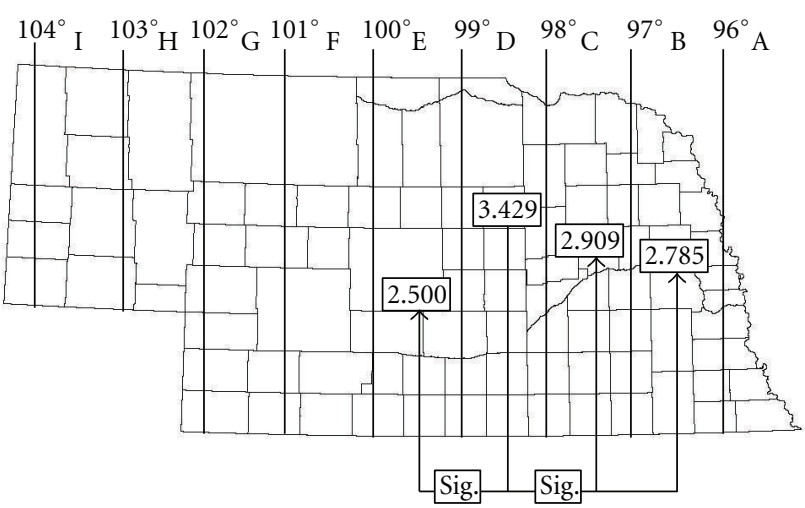

(a)

\section{Long fixed effects: $P=0.0066 \quad$ Lat $*$ long fixed effects: $P=0.0862$}

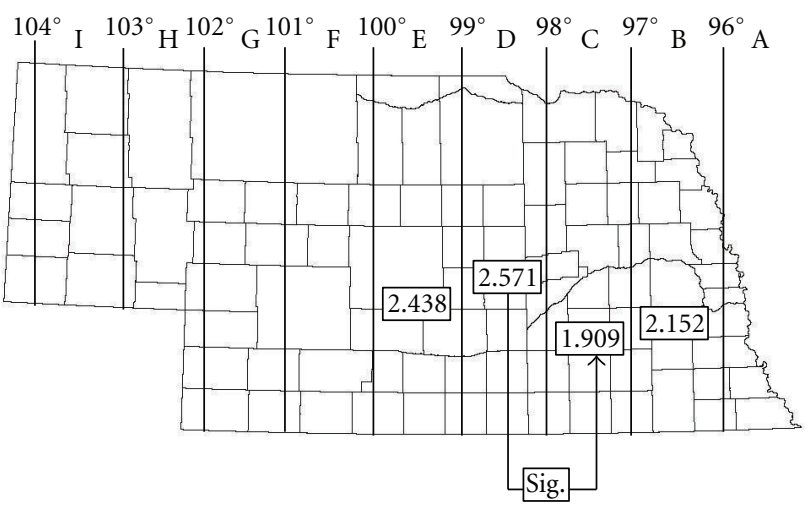

(b)

Figure 2: Elytral maculation character states for C. limbalis (adapted from [18]). (a) Middle band and (b) apical lunule. Total maculation and humeral lunule not presented as no significant differences found. Significant differences between longitudes shown by arrows and mean value presented in each longitudinal grouping. Fixed effects and effects of latitude by longitude interactions presented at top of each map. 


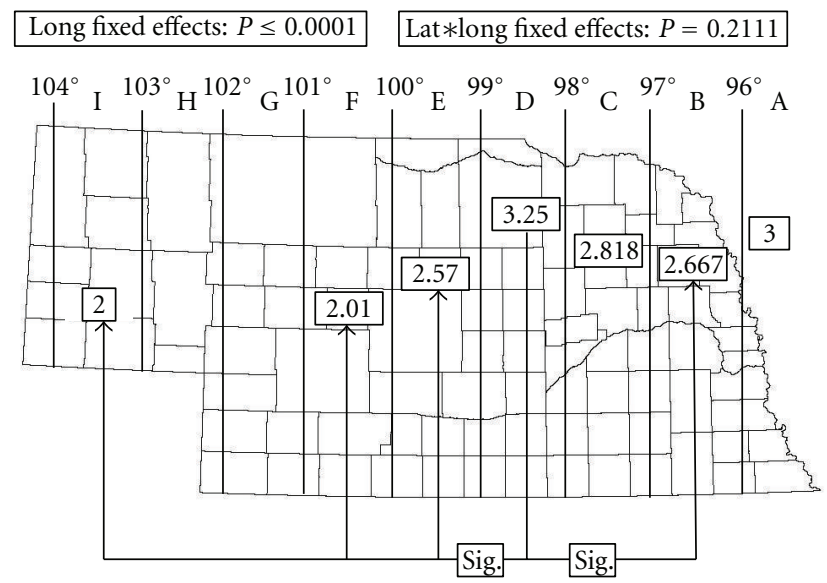

(a)
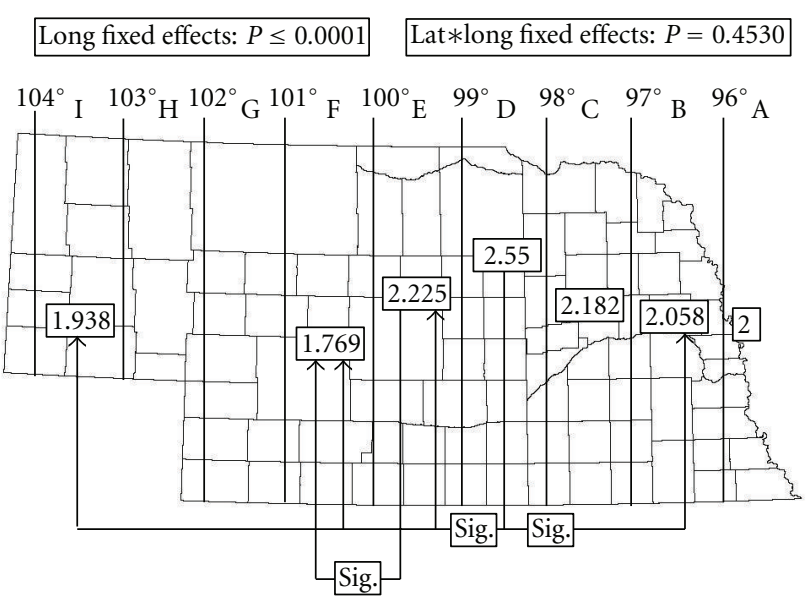

(b)

Figure 3: Elytral maculation character states for C. splendida (adapted from [18]). (a) Middle band and (b) apical lunule. Total maculation and humeral lunule not presented as no significant differences found. Significant differences between longitudes shown by arrows and mean value presented in each longitudinal grouping. Fixed effects and effects of latitude by longitude interactions presented at top of each map.

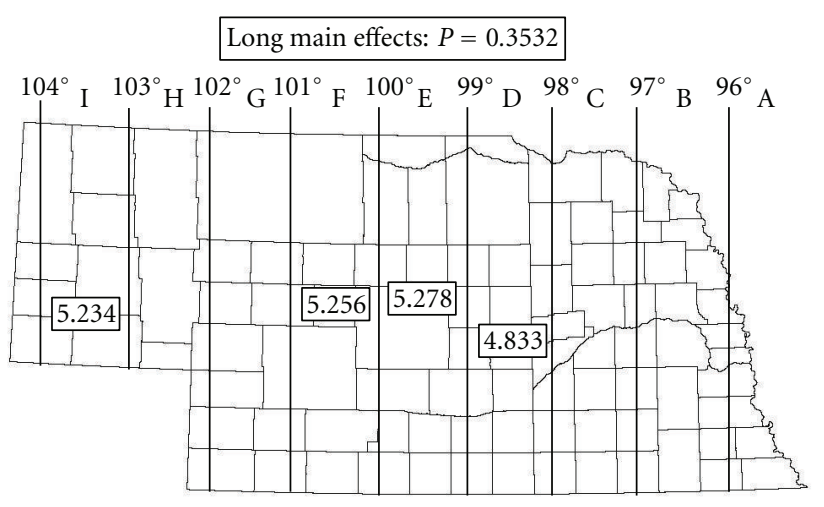

FIGURe 4: Mean elytral color by code for Cicindela denverensis by longitudinal region. Significant differences between longitudes shown by arrows and mean value presented in each longitudinal grouping. Fixed effects presented at top. No latitude by longitude interactions found.

conducted because environmental conditions can influence adult coloration patterns [25]. Because Nebraska's tiger beetle fauna consists of 32 species and most counties have 8 or less [16], the inability to properly identify species or the presence of hybrids will affect estimates of biological diversity.

In Nebraska, the apparent hybrid zone affects parts of at least seven counties and approximately $20 \%$ of the state (Figure 12). The geographic and morphological analyses indicate a hybrid zone extending from central Custer and Dawson Counties east to the eastern third of Valley and Hall Counties (Figure 12). The termination of this hybrid zone to the north and south coincides with a general lack of suitable habitat as the Rainwater Basin occurs south of this area, and the Sand Hills occur to the north.

In the eastern half of the hybrid zone, all three species cooccur west at least to Kearney. Nearly all of the C. limbalis collected in this area exhibit at least a moderate greenish hue,

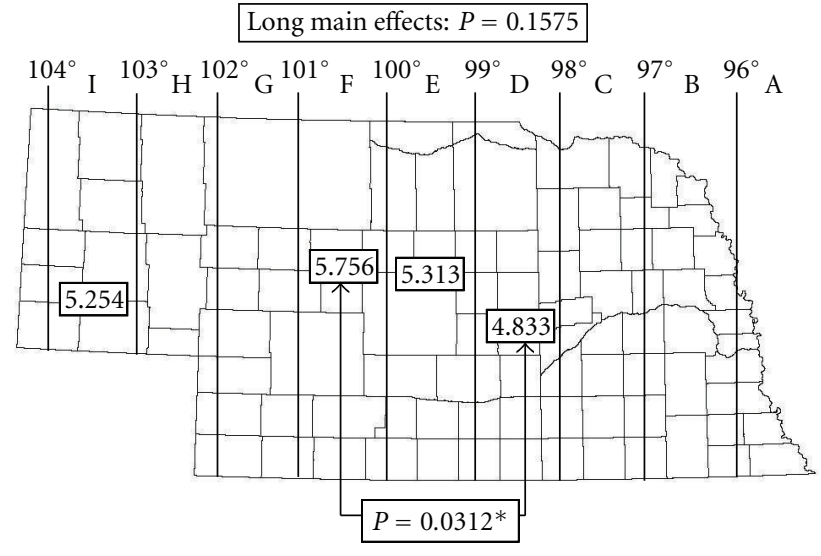

Figure 5: Mean pronotal color by code for Cicindela denverensis by longitudinal region. Significant differences between longitudes shown by arrows and mean value presented in each longitudinal grouping. Fixed effects presented at top. No latitude by longitude interactions found.

suggesting hybridization with $C$. denverensis. Greenish $C$. limbalis have been recorded in other areas as well $[26,27]$, mostly where $C$. denverensis and $C$. limbalis cooccur. Across the entire zone, the majority (especially toward the east) exhibit coppery bronze to greenish elytra, which in some cases might suggest the "ludoviciana" [28] phenotype. However, the majority of these specimens have a green to bluish green pronotum, while in "ludoviciana" the pronotum is deep blue. Some specimens have variable amounts of coppery bronze on the anterior parts of the elytra, diffusing into green elsewhere. For the analyses, these were classified as coppery green, but, importantly, this phenotype has not been previously documented in $C$. splendida elsewhere in its range. Interestingly, specimens with features suggesting hybridization between C. limbalis and C. splendida were found only on the eastern edge of the hybrid zone. 


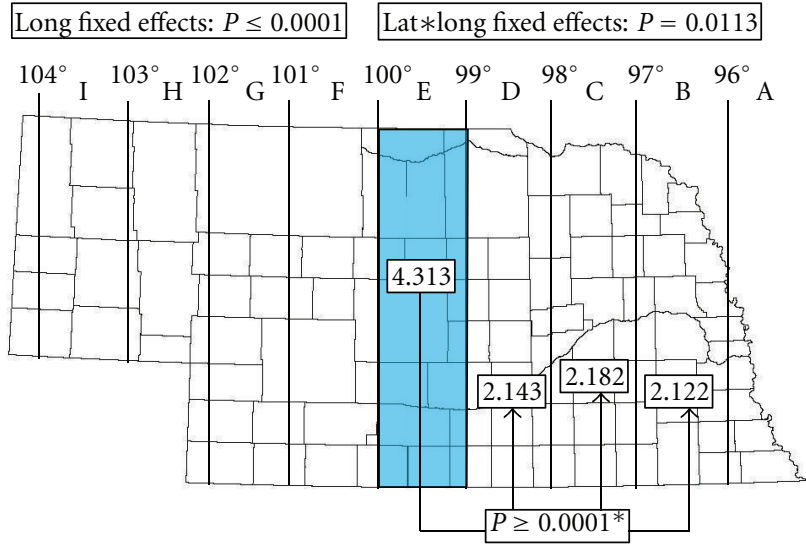

Figure 6: Mean elytral color by code for Cicindela limbalis by longitudinal region. Significant differences between longitudes shown by arrows and mean value presented in each longitudinal grouping. Fixed effects presented at top. No latitude by longitude interactions found. Shaded area depicts longitudinal regions differing from all others.

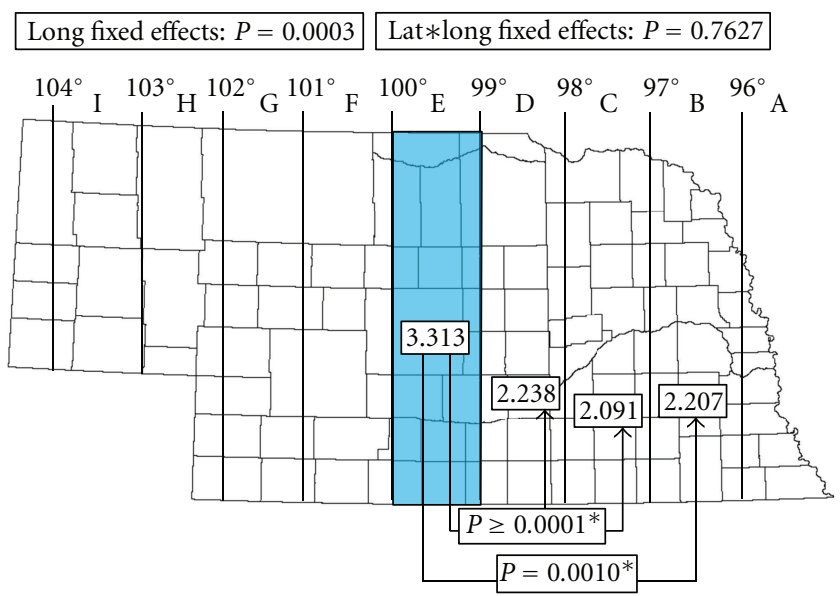

Figure 7: Mean pronotal color by code for Cicindela limbalis by longitudinal region. Significant differences between longitudes shown by arrows and mean value presented in each longitudinal grouping. Fixed effects presented at top. No latitude by longitude interactions found. Shaded area depicts longitudinal regions differing from others.

Observed hybridization among members of the butterfly genus Liminitis in North America appears correlated to one species occurring at extremely low densities alongside a sister species that is more numerous. Under such conditions, a male of the rare species may choose to mate with a female of the more common species if he is unable to find a mate of his own species [29]. However, Wirtz [30] concluded in a review of the literature that females are the choosier sex and that in most cases females of rare species will mate with males of more common species as a last resort. Although genetic analysis is needed to determine the direction of crossing in these species in Nebraska, rarity of individuals of a species appears to contribute to interbreeding at least for C. limbalis.

Rarity of individuals does not appear to explain intergrades between $C$. denverensis and C. splendida which often
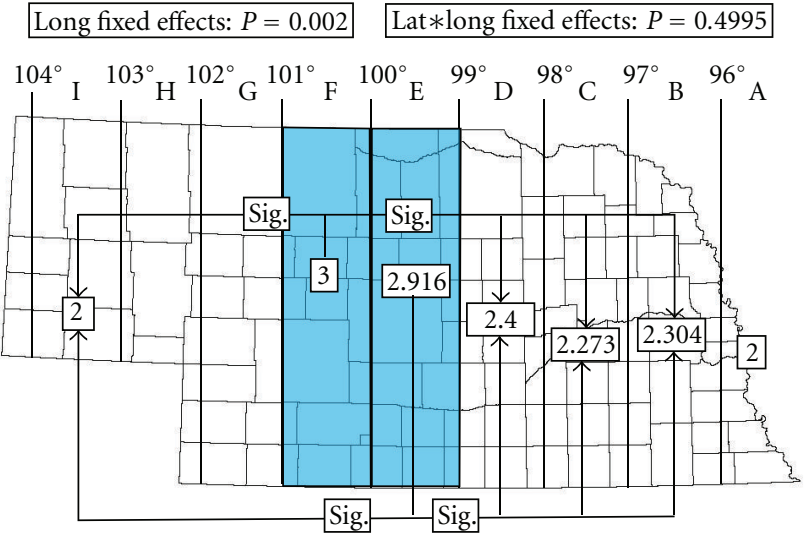

Figure 8: Mean elytral color by code for Cicindela splendida by longitudinal region. Significant differences between longitudes shown by arrows and mean value presented in each longitudinal grouping. Fixed effects presented at top. No latitude by longitude interactions found. Shaded area depicts longitudinal regions differing from others.

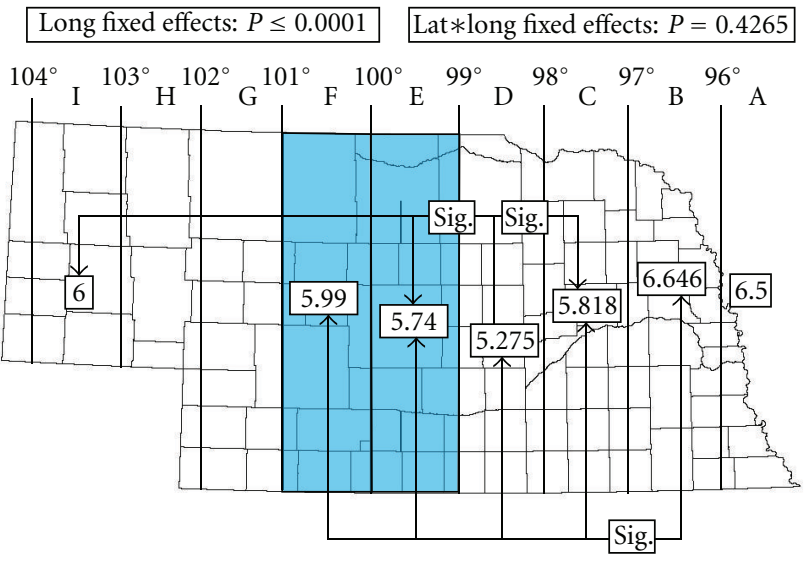

FiguRe 9: Mean pronotal color by code for Cicindela splendida by longitudinal region. Significant differences between longitudes shown by arrows and mean value presented in each longitudinal grouping. Fixed effects presented at top. No latitude by longitude interactions found. Shaded area depicts longitudinal regions differing from all others except each other.

and widely co-occur in Nebraska and elsewhere with little evidence of interbreeding. It does seem possible that hybridization between $C$. denverensis and C. limbalis could lead to a cascade of hybridization events perhaps causing hybrid offspring to interbreed with any of the three species, resulting in offspring of a broad range of phenotypes. Elsewhere, C. denverensis and $C$. limbalis may hybridize where they cooccur, but they are mostly geographically separated, potentially as a result of differing moisture preferences. In Colorado, Kippenhan [31] reported few locations where both species had been collected. It appears that $C$. limbalis dominates sites with a long and stable history. For example, although the steep loess bluffs in Fremont County Iowa just across the Missouri River from Nebraska City present habitat suitable for C. limbalis and C. splendida and are within the range 


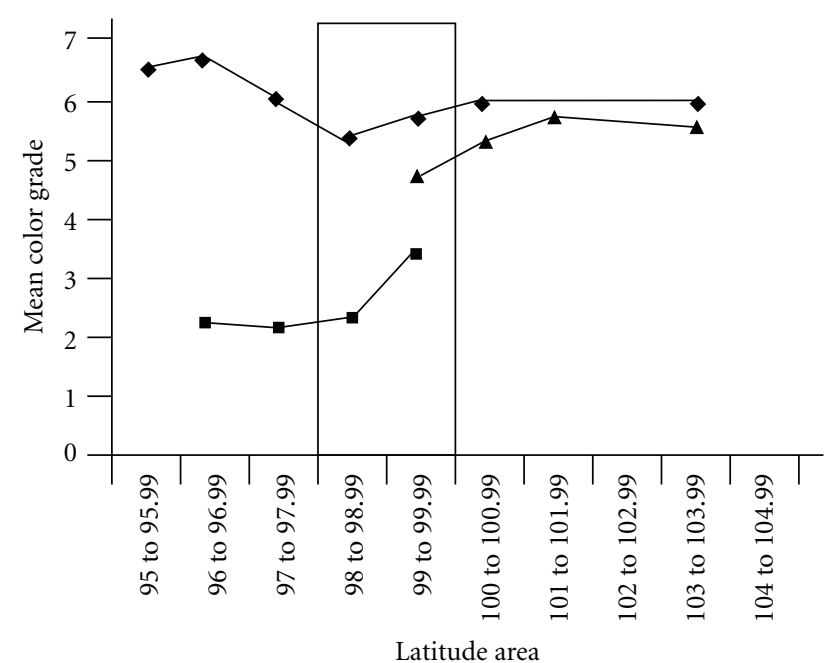

- C. denverensis

- C. limbalis

- C. splendida

Figure 10: Graph of mean pronotal color by code for C. denverensis, C. limbalis, and C. splendida by longitude. Region of character convergence for $C$. denverensis and $C$. splendida depicted by rectangle.

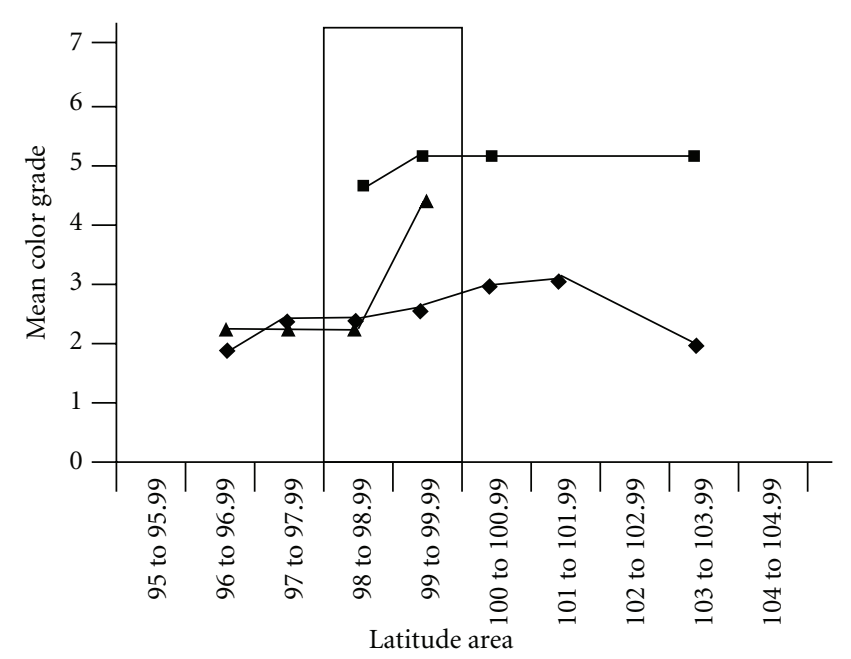

- C. denverensis

- C. limbalis

- C. splendida

Figure 11: Graph of mean elytral color by code for C. denverensis, C. limbalis, and C. splendida by longitude. Region of character convergence for $C$. denverensis and C. splendida depicted by rectangle.

of both species, C. limbalis is common while C. splendida is rare there. Thus, disturbance, either from natural causes or anthropomorphic changes, may also influence the hybrid zone.

It is also unknown if the location of the hybrid zone is stable over time. Dasmahapatra et al. [32] found that a hybrid zone in the lepidopteran genus Anartia had moved significantly in Central America over a twenty-year period. Future collection in the hybrid zone in Nebraska should reveal if the

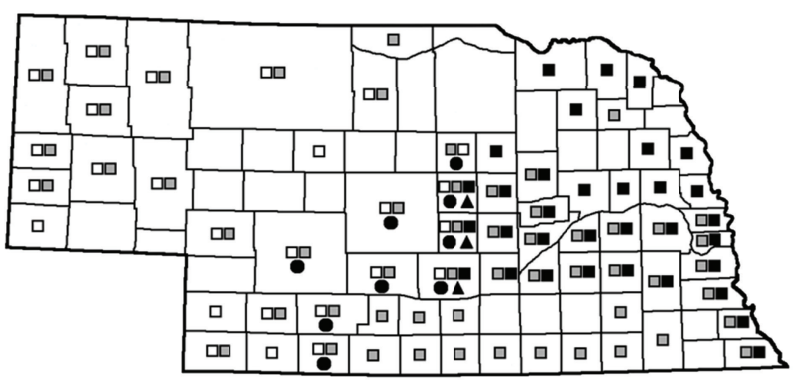

Figure 12: Approximate delineation of hybrid zones in the Cicindela splendida group in Nebraska. The occurrence of $C$. denverensis is depicted by an empty square, $C$. splendida by a gray square, and C. limbalis by a black square. A black circle indicates presence of $C$. denverensis $\times$ splendida hybrids, and a black triangle indicates the presence of $C$. limbalis $\times$ denverensis hybrids.

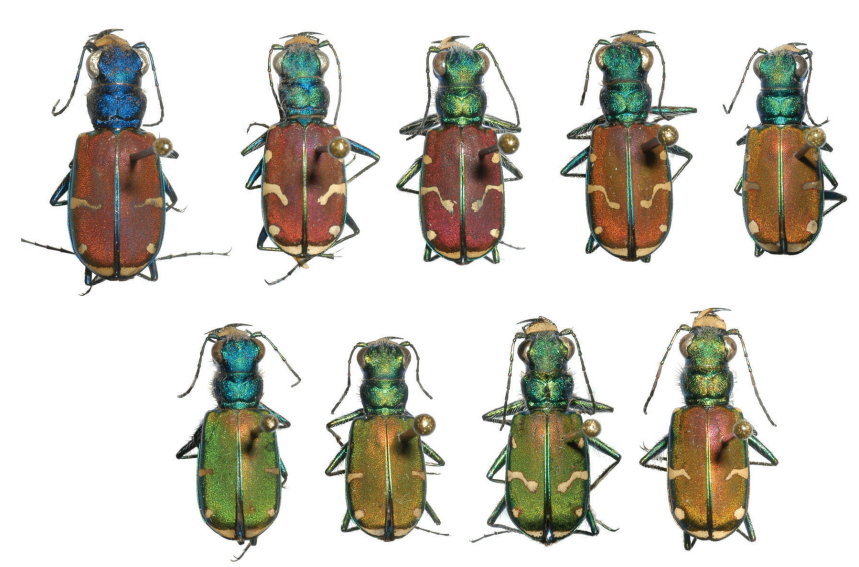

FIGURE 13: Series of Cicindela splendida showing variation in maculation and color. Top row: Largely pure C. splendida, bottom row: Hybrid $C$. denverensis $\times$ splendida.

zone is spatially stable. It is also unknown if the hybrids suffer from reduced fitness as has been found in some other studies [33-35].

Finally, it is unknown whether assortative mating [36, 37], female choice, or male choice are the major factors influencing the hybrid zone. Male tiger beetles will attempt to mate with nearly any other tiger beetle of similar size [38]. Thus, it may be that females make the final choice in determining if the spermatophore is suitable. It is also possible that the dispersal ability of each of these three species may also play a role in cooccurrence [39]. Carter [40] suggested that $C$. limbalis did not colonize new sites as rapidly as $C$. splendida, and this matches our own observations.

Mitochondrial studies used to distinguish between closely related species are sometimes of limited value. For example, Schmidt and Sperling [3] suggested that rare hybridization between tiger moth species in the genus Grammia might explain why their mtDNA tree appeared to follow geographic distribution rather than previously supported phylogeny. The authors also suggested that while mtDNA analyses can 
be misleading for distinguishing closely related species, these tools are an excellent tool for detecting hybridization [3]. Of particular interest in such cases is why such mitochondrial lineages are passed on and proliferate. Perhaps such phenomena support the hybrid vigor hypothesis.

Mitochondrial DNA evidence suggests that all three species in the C. splendida group may represent a single variable species [22, 24]. However, ecological preferences and the complex phenotypic interrelationships between these forms suggests otherwise. Even the concept of subspecies does not apply as this would suggest that across much of the United States, two subspecies occur sympatrically without interbreeding. The remaining explanations are (1) unique phenotypes within a single species which affect coloration, mating preference, and habitat associations, perhaps as a result of differing selection pressures, (2) ecological species, or (3) a ring species phenomenon.

If the first explanation is correct, it would suggest a group in the process of speciation. Indeed, if phenotype affects mating preference, this would largely keep each of these forms distinct. It is apparent that while males will attempt to mate with females of any of these three forms, many observed matings between forms resulted in rejection of the spermatophore [20]. Both the second and third explanations suggest overlaps in habitat preference, but differences in optimal habitat. If these tiger beetles qualify as a ring species, the geographic pattern of phenotypes suggests that $C$. denverensis would form the middle of the ring, and $C$. limbalis and $C$. splendida the two ends. If this phylogenetic relationship is true, it would differ from the hypothesis presented by Schincariol and Freitag [18], who suggested that $C$. limbalis is most representative of the ancestral form, that $C$. denverensis represents an early split, and that C. splendida represents a later split from a $C$. limbalis type ancestor.

While the biological species concept suggests that the occurrence of any hybrids represents incomplete speciation $[41,42]$, the fact that these three tiger beetle species maintain their integrity over most of their range suggests that they "function" as individual species in most areas. For now, based on morphological and mating studies, it appears that $C$. denverensis is phylogenetically closer to both $C$. limbalis and $C$. splendida than these two species are to each other. Perhaps more sensitive genetic studies may reveal the true phylogenetic relationships among these three species. This study is an example of the difficulty in applying species concepts for closely related species that differ in a small number of characters and hybridize in at least limited areas.

This study shows the complexity of species definitions, especially based on color morphologies. Across much of their ranges, these forms function as distinct species; however, the observed hybrid zone in central Nebraska causes the validity of this conclusion to be questioned. Our findings have important implications for conservation and for monitoring biological diversity. Based on the frequency of hybridization in this group of species in Nebraska all three species could be lumped into a single species. Alternatively, if only morphology is used, hybrids could be viewed as different species, leading to the possibility of four or five species being present.
Doing rapid biodiversity assessment in central Nebraska using tiger beetles could result in either underestimating or overestimating tiger beetle diversity or both if citizen scientists were used for these surveys [6].

In Nebraska, the Salt Creek tiger beetle, Cicindela nevadica lincolniana Casey, is a federally endangered subspecies of the much more widely distributed C. nevadica [43]. Thus, the designations of subspecies based on phenotypes can have important consequences for conservation as well. Our findings of morphological variation and hybridization among multiple species suggests that tiger beetle taxonomy based on morphological characters alone should be cautiously interpreted and that additional research using molecular and behavioral techniques is warranted. Because tiger beetles are among the most charismatic and well-studied beetle groups, it is likely that similar or even greater problems will be encountered for other beetle groups that are potential indicators of ecosystem changes.

\section{References}

[1] T. E. Dowling and C. L. Secor, "The role of hybridization and introgression in the diversification of animals," Annual Review of Ecology and Systematics, vol. 28, pp. 593-619, 1997.

[2] J. Epifanio and J. Nielsen, "The role of hybridization in the distribution, conservation and management of aquatic species," Reviews in Fish Biology and Fisheries, vol. 10, pp. 245-251, 2000.

[3] B. C. Schmidt and F. A. H. Sperling, "Widespread decoupling of mtDNA variation and species integrity in Grammia tiger moths (Lepidoptera: Noctuidae)," Systematic Entomology, vol. 33, no. 4, pp. 613-634, 2008.

[4] K. Schwenk, N. Brede, and B. Streit, "Introduction. Extent, processes and evolutionary impact of interspecific hybridization in animals," Philosophical Transactions of the Royal Society B, vol. 363, no. 1505, pp. 2805-2811, 2008.

[5] F. W. Allendorf, R. F. Leary, P. Spruell, and J. K. Wenburg, "The problems with hybrids: setting conservation guidelines," Trends in Ecology and Evolution, vol. 16, no. 11, pp. 613-622, 2001.

[6] B. Savan, A. J. Morgan, and C. Gore, "Volunteer environmental monitoring and the role of the universities: the case of Citizens' Environment Watch," Environmental Management, vol. 31, no. 5, pp. 561-568, 2003.

[7] D. G. Delaney, C. D. Sperling, C. S. Adams, and B. Leung, "Marine invasive species: validation of citizen science and implications for national monitoring networks," Biological Invasions, vol. 10, no. 1, pp. 117-128, 2008.

[8] J. E. Losey, J. E. Perlman, and E. R. Hoebeke, "Citizen scientist rediscovers rare nine-spotted lady beetle, Coccinella novemnotata, in eastern North America," Journal of Insect Conservation, vol. 11, no. 4, pp. 415-417, 2007.

[9] E. Howard and A. K. Davis, "The fall migration flyways of monarch butterflies in eastern North America revealed by citizen scientists," Journal of Insect Conservation, vol. 13, no. 3, pp. 279-286, 2009.

[10] K. L. Kelly and D. B. Judd, Color: universal Language and Dictionary of Names, National Bureau of Standards, 1976.

[11] D. L. Pearson, C. B. Knisley, and C. J. Kazilek, A Field Guide to Tiger Beetles of the United States and Canada: identification, Natural History, and Distribution of the Cicindelidae, Oxford University Press, New York, NY, USA, 2006. 
[12] D. L. Pearson and F. Cassola, "Are we doomed to repeat history? A model of the past using tiger beetles (Coleoptera: Cicindelidae) and conservation biology to anticipate the future," Journal of Insect Conservation, vol. 11, no. 1, pp. 47-59, 2007.

[13] S. S. Carroll and D. L. Pearson, "Spatial modeling of butterfly species richness using tiger beetles (Cicindelidae) as a bioindicator taxon," Ecological Applications, vol. 8, no. 2, pp. 531-543, 1998.

[14] F. Cassola and D. L. Pearson, "Global patterns of tiger beetle species richness (Coleoptera: Cicindelidae): their use in conservation planning," Biological Conservation, vol. 95, no. 2, pp. 197-208, 2000.

[15] D. L. Pearson and S. S. Carroll, "Predicting patterns of tiger beetle (Coleoptera: Cicindelidae) species richness in northwestern south america," Studies on Neotropical Fauna and Environment, vol. 36, no. 2, pp. 125-136, 2001.

[16] M. L. Brust, W. W. Hoback, S. M. Spomer, W. J. Allgeier, and P. D. Nabity, "New tiger beetle county records for Nebraska," U.S.A. Cicindela, vol. 37, pp. 37-58, 2005.

[17] M. L. Brust, "New tiger beetle observations and county records for Nebraska and a new state record for Cicindela tenuisignata LeConte," Cicindela, vol. 38, pp. 9-15, 2006.

[18] L. A. Schincariol and R. Freitag, "Biological character analysis, classification, and history of the North American Cicindela splendida Hentz group taxa (Coleoptera: Cicindelidae)," Canadian Entomologist, vol. 123, no. 6, pp. 1327-1353, 1991.

[19] W. N. Johnson, "Sympatric population of Cicindela limbalis transversa and Cicindela splendida cyanocephalata," Cicindela, vol. 11, article 26, 1979.

[20] L. A. Schincariol, Mating behaviour, spermatophore structure, ecology and systematics of the Cicindela splendida group (Coleoptera: Cicindelidae), M.S. thesis, Lakehead University, Ontario, USA, 1988.

[21] SAS Institute Inc, The GLM Procedure, SAS Institute Inc, Cary, NC, USA, 1999.

[22] C. B. Knisley and T. D. Schultz, The Biology of Tiger Beetles and a Guide to the Species of the South Atlantic States, Virginia Museum of Natural History, Martinsville, Va, USA, 1976.

[23] A. P. Vogler, R. Desalle, T. Assmann, C. B. Knisley, and T. D. Schultz, "Molecular population genetics of the endangered tiger beetle Cicindela dorsalis (Coleoptera: Cicindelidae)," Annals of the Entomological Society of America, vol. 86, pp. 142$152,1993$.

[24] R. M. Woodcock and C. B. Knisley, "Genetic analysis of an unusual population of the problematic tiger beetle group, Cicindela Spendida/C. Limbalis, from Virginia, U.S.A. (Coleoptera: Cicindelidae) using mtDNA," Entomological News, vol. 120, no. 4, pp. 341-348, 2009.

[25] V. E. Shelford, "Color and color-pattern mechanism of tiger beetles," Illinois Biological Monographs, vol. 3, pp. 395-592, 1917.

[26] B. Cutler, "An unusual series of Cicindela limbalis from South Dakota," Cicindela, vol. 1, pp. 5-7, 1969.

[27] J. Acorn, Tiger Beetle of Alberta: Killers on the Clay, Stalkers on the Sand, University of Alberta Press, Edmonton, Alberta, 2001.

[28] C. W. Leng, "Notes on the Cicindelidae of Louisiana," Journal of the New York Entomological Society, vol. 10, pp. 131-136, 1902.

[29] A. P. Platt and J. R. Maudsley, "Continued interspecific hybridization between Limenitis (Basilarchia) arthemis astyanax and L. (B.) archippus in the southeastern U.S. (Nymphalidae)," Journal of the Lepidopterists' Society, vol. 48, pp. 190-198, 1994.
[30] P. Wirtz, "Mother species-father species: unidirectional hybridization in animals with female choice," Animal Behaviour, vol. 58, no. 1, pp. 1-12, 1999.

[31] M. G. Kippenhan, "The tiger beetles (Coleoptera: Cicindelidae) of Colorado," Transactions of the American Entomological Society, vol. 120, pp. 1-86, 1994.

[32] K. K. Dasmahapatra, M. J. Blum, A. Aiello et al., "Inferences from a rapidly moving hybrid zone," Evolution, vol. 56, no. 4, pp. 741-753, 2002.

[33] N. H. Barton and G. M. Hewitt, "Analysis of hybrid zones," Annual Review of Ecology and Systematics, vol. 16, pp. 113-148, 1985.

[34] N. H. Barton and G. M. Hewitt, "Adaptation, speciation and hybrid zones," Nature, vol. 341, no. 6242, pp. 497-503, 1989.

[35] F. A. H. Sperling and J. R. Spence, "Structure of an asymmetric hybrid zone between two water strider species (Hemiptera: Gerridae: Limnoporus)," Evolution, vol. 45, no. 6, pp. 1370 1383, 1991.

[36] S. R. Virdee and G. M. Hewitt, "Clines for hybrid dysfunction in a grasshopper hybrid zone," Evolution, vol. 48, no. 2, pp. 392-407, 1994.

[37] M. G. Ritchie, R. K. Butlin, and G. M. Hewitt, "Fitness consequences of potential assortative mating inside and outside a hybrid zone in Chorthippus parallelus (Orthoptera: Acrididae): implications for reinforcement and sexual selection theory," Biological Journal of the Linnean Society, vol. 45, no. 3, pp. 219-234, 1992.

[38] D. L. Pearson and A. P. Vogler, Tiger Beetles: The Evolution, Ecology, and Diversity of the Cicindelids, Cornell University Press, Ithaca, NY, USA, 2001.

[39] R. A. Nichols, "The fragmentation of tension zones in sparsely populated areas," American Naturalist, vol. 134, pp. 969-977, 1989.

[40] M. R. Carter, "The biology and ecology of the tiger beetles (Coleoptera: Cicindelidae) of Nebraska," Transactions of the Nebraska Academy of Sciences, vol. 17, pp. 1-18, 1989.

[41] T. Dobzhansky, Ed., Genetics and the Origin of Species, Columbia University Press, New York, NY, USA, 3rd edition, 1951.

[42] E. Mayr, "Speciation phenomena in birds," American Naturalist, vol. 74, pp. 249-278, 1940.

[43] S. M. Spomer and L. G. Higley, "Population status and distribution of the Salt Creek tiger beetle, Cicindela nevadica lincolniana Casey (Coleoptera: Cicindelidae)," Journal of the Kansas Entomological Society, vol. 66, no. 4, pp. 392-398, 1993. 

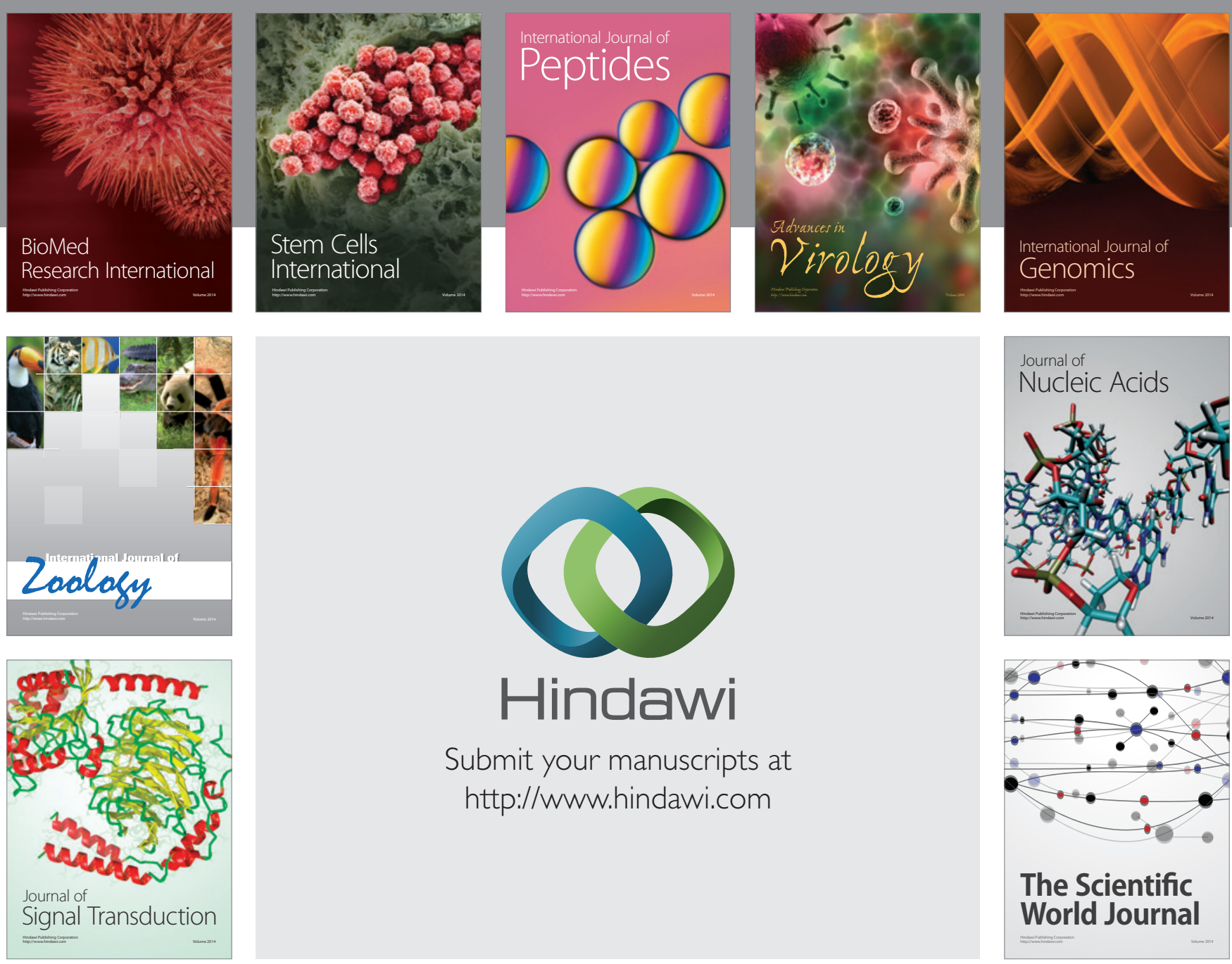

Submit your manuscripts at

http://www.hindawi.com
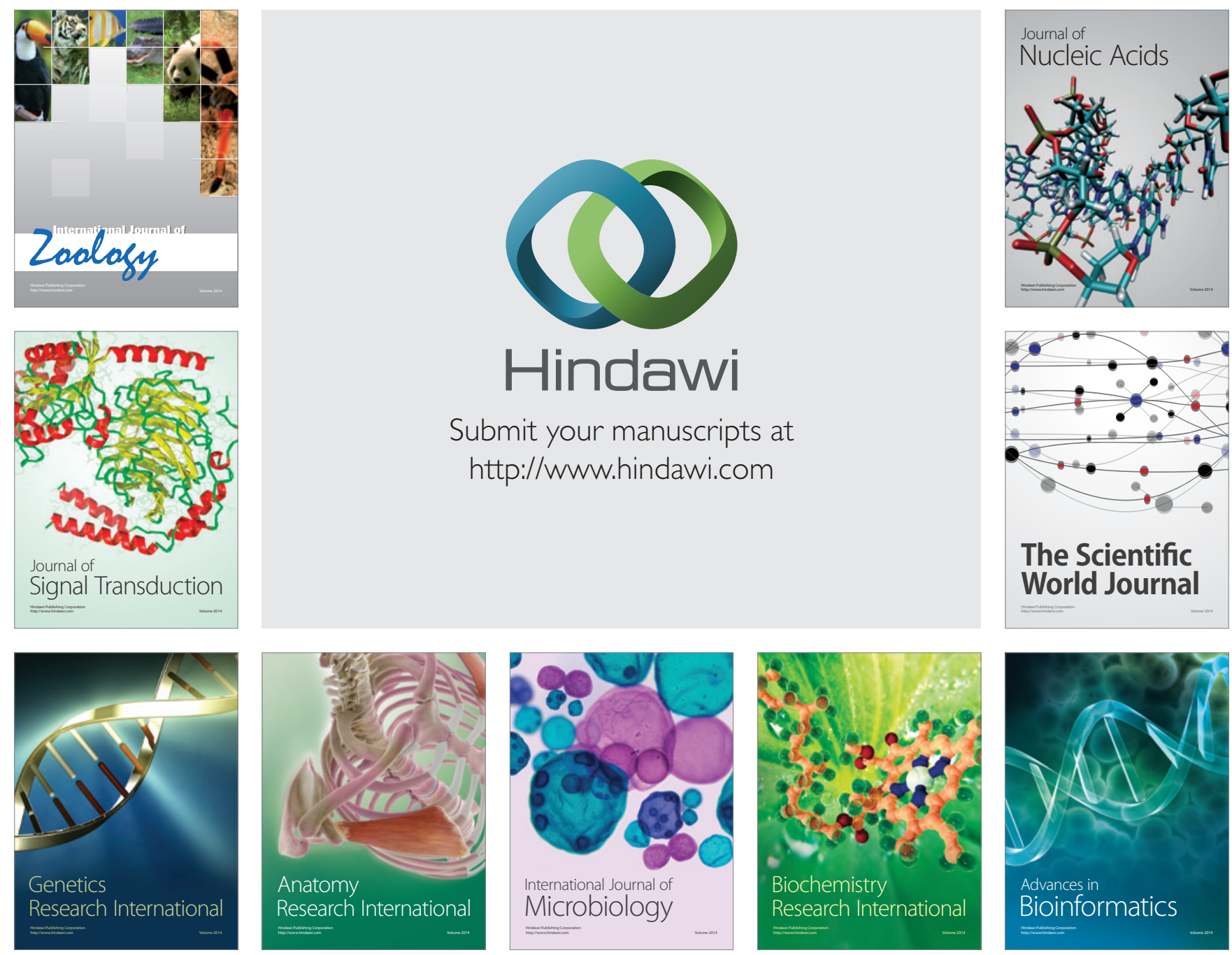

The Scientific World Journal
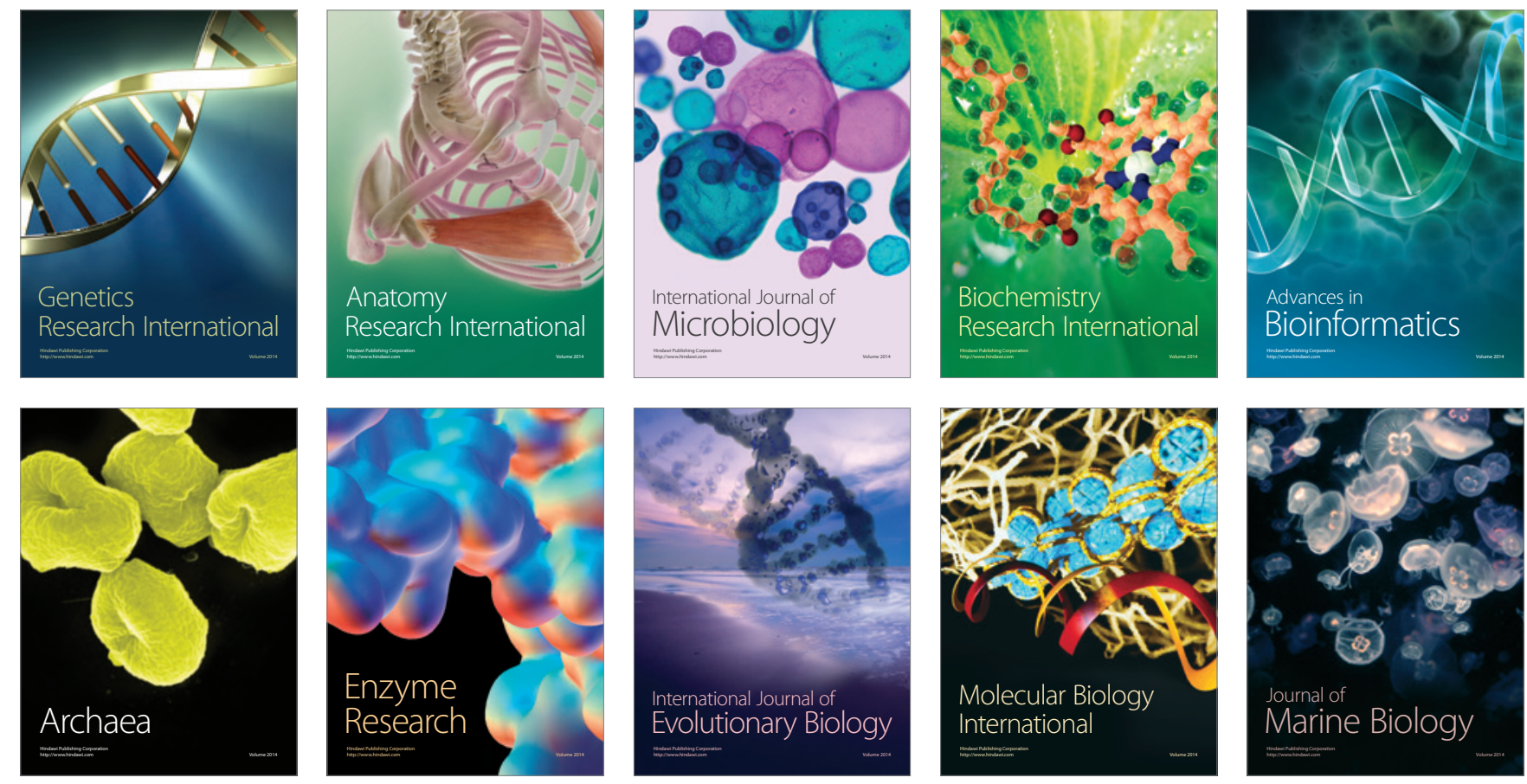